\title{
Commentary: 20-Year Trends in the Pharmacologic Treatment of Bipolar Disorder by Psychiatrists in Outpatient Care Settings
}

\author{
Bruno Etain ${ }^{1,2,3}$, Emilie Olie ${ }^{3,4 *}$, Philippe Courtet ${ }^{3,4}$, Ophelia Godin ${ }^{3,5}$ and Marion Leboyer ${ }^{3,5}$ \\ ${ }^{1}$ Université de Paris - INSERM UMRS 1144, Paris, France, ${ }^{2}$ Assistance Publique des Hôpitaux de Paris, APHP.Nord, DMU \\ Neurosciences, GHU Saint Louis-Lariboisière-Fernand Widal, Département de Psychiatrie et de Médecine Addictologique, \\ Paris, France, ${ }^{3}$ Fondation Fondamental, Créteil, France, ${ }^{4}$ Department of Emergency Psychiatry and Acute Care, Lapeyronie \\ Hospital, PSNREC, Univ Montpellier, INSERM, CHU de Montpellier, Montpellier, France, ${ }^{5}$ Université Paris Est Créteil, Inserm \\ U955, IMRB, Laboratoire Neuro-Psychiatrie Translationnelle, Créteil, France
}

Keywords: bipolar disorder, antipsychotics, suicide, lithium, metabolic syndrome

\section{A Commentary on}

OPEN ACCESS

Edited by: Andrea Fagiolini,

University of Siena, Italy

Reviewed by:

Steven Marwaha, University of Birmingham, United Kingdom

*Correspondence: Emilie Olie

e-olie@chu-montpellier.fr

Specialty section: This article was submitted to Mood and Anxiety Disorders,

a section of the journal

Frontiers in Psychiatry

Received: 07 August 2020 Accepted: 10 December 2020 Published: 15 January 2021

Citation:

Etain B, Olie E, Courtet P, Godin O and Leboyer M (2021) Commentary: 20-Year Trends in the Pharmacologic

Treatment of Bipolar Disorder by

Psychiatrists in Outpatient Care Settings. Front. Psychiatry 11:592593.

doi: 10.3389/fpsyt.2020.592593
20-Year Trends in the Pharmacologic Treatment of Bipolar Disorder by Psychiatrists in Outpatient Care Settings

by Rhee, T. G., Olfson, M., Nierenberg, A. A., and Wilkinson, S. T. (2020). Am. J. Psychiatry 177, 706-715. doi: 10.1176/appi.ajp.2020.19091000

\section{INTRODUCTION}

Using data from the US care system over 20 years, Rhee and colleagues (1) reported in the American Journal of Psychiatry (July 2020) that, among outpatients with Bipolar Disorder (BD), the prescriptions of second-generation antipsychotics (SGAs) massively increased (from $12.4 \%$ of BD outpatient in the $1997-2000$ period to $51.4 \%$ in the $2013-2016$ period), while the prescriptions of lithium and anticonvulsants decreased (from 62.3\% of BD patients in the 1997-2000 period to $26.4 \%$ in the 2013-2016 period). The use of antidepressants, whose efficacy in bipolar depression is limited (2), constantly rose during the same period, these being often prescribed without any mood stabilizer (40.9\% in the $2013-2016$ period) in about half of the visits.

\section{THE GROWING USE OF SECOND GENERATION ANTIPSYCHOTICS IS QUESTIONABLE}

This shift from lithium/anticonvulsants to SGAs prescriptions is also observed in Europe $(3,4)$. This trend was expected because most SGAs have been marketed during the last two decades. RCTs published by drug companies made SGAs mechanically going up to the top of the list of recommended medications in recent guidelines. While formally approved in $\mathrm{BD}$, the rising use of SGAs is nonetheless alarming as it is associated with metabolic syndrome (5). Metabolic syndrome, which is associated with a 2 -fold higher rate of cardiovascular outcomes and a 1.5fold higher all-cause mortality rate, affects $37 \%$ of patients with BD (6). Efforts are therefore required to bend this curve of SGAs prescriptions to prevent any potential long-term harm. 
The decreasing use of lithium would certainly be viewed as a non-sense by many clinicians. Beyond its proven efficacy as a mood stabilizer, lithium is also known to reduce suicidal risk in $\mathrm{BD}$ (7). About one-third to one-half of $\mathrm{BD}$ patients attempt suicide at least once in their lifetime and approximately $15-20 \%$ die due to suicide. Not only recommended for the prevention of mood recurrences, lithium also decreases suicidal risk in $\mathrm{BD}$, a striking advantage for a disorder for which the burden of suicide is major. Experts in the field regularly advocate for a renewal of lithium use despite its observed decline. Although it is undoubtedly easier to prescribe SGAs as first line agents (however, just a short-term option), clinicians should beware of the belief that SGAs necessarily provide a better benefit/risk balance. Hence, we should relentlessly argue that lithium offers an efficacious and safe option in BD which helps reduce the high rates of mortality due to suicide and natural causes.

The choice of medication has thus an impact on premature mortality in $\mathrm{BD}$ patients largely due to cardiovascular disease and suicide (8).

\section{REFERENCES}

1. Rhee TG, Olfson M, Nierenberg AA, Wilkinson ST. 20-year trends in the pharmacologic treatment of bipolar disorder by psychiatrists in outpatient care settings. Am J Psychiatry. (2020) 177:706-15. doi: 10.1176/appi.ajp.2020.19091000

2. Carvalho AF, Firth J, Vieta E. Bipolar disorder. N Engl J Med. (2020) 383:5866. doi: 10.1056/NEJMra1906193

3. Bohlken J, Bauer M, Kostev K. Drug treatment for patients with bipolar disorders in psychiatric practices in Germany in 2009 and 2018. Psychiatry Res. (2020) 289:112965. doi: 10.1016/j.psychres.2020.112965

4. Lyall LM, Penades N, Smith DJ. Changes in prescribing for bipolar disorder between 2009 and 2016: national-level data linkage study in Scotland. $\mathrm{Br} J$ Psychiatry. (2019) 215:415-21. doi: 10.1192/bjp.2019.16

5. Barton BB, Segger F, Fischer K, Obermeier M, Musil R. Update on weight-gain caused by antipsychotics: a systematic review and meta-analysis. Expert Opin Drug Safety. (2020) 19:295-314. doi: 10.1080/14740338.2020.1713091

6. Vancampfort D, Vansteelandt K, Correll CU, Mitchell AJ, De Herdt A, Sienaert $\mathrm{P}$, et al. Metabolic syndrome and metabolic abnormalities in bipolar disorder: a meta-analysis of prevalence rates and moderators. Am J Psychiatry. (2013) 170:265-74. doi: 10.1176/appi.ajp.2012.12050620

7. Del Matto L, Muscas M, Murru A, Verdolini N, Anmella G, Fico G, et al. Lithium and suicide prevention in mood disorders and in the general

\section{DISCUSSION}

A decade ago, the "Fondamental Foundation" created the French Network of Centers of Expertise which offers recommendations for personalized care plans in BD. During a 2 years followup, we observed significant changes in the medications being prescribed [i.e., higher use of lithium or anticonvulsants, lower use of antidepressants, and in parallel, an improvement of the course of BD (i.e. mood episodes, hospitalizations) (9)]. We suggest that such centers can help guaranteeing a rationale and personalized use of medications in BD (personalized choice of mood stabilizers and a cautious use of antidepressants), in agreement with guidelines. Expertise should counterbalance common practices.

\section{AUTHOR CONTRIBUTIONS}

$\mathrm{BE}$ and $\mathrm{EO}$ wrote the draft of the manuscript. OG, PC, and ML actively revised the manuscript. All authors contributed to the article and approved the submitted version.

population: a systematic review. Neurosci Biobehav Rev. (2020) 116:14253. doi: 10.1016/j.neubiorev.2020.06.017

8. Osby U, Brandt L, Correia N, Ekbom A, Sparen P. Excess mortality in bipolar and unipolar disorder in Sweden. Arch Gen Psychiatry. (2001) 58:84450. doi: 10.1001/archpsyc.58.9.844

9. Henry C, Godin O, Courtet P, Azorin JM, Gard S, Bellivier $\mathrm{F}$, et al. Outcomes for bipolar patients assessed in the French expert center network: a 2-year follow-up observational study (FondaMental Advanced Centers of Expertise for Bipolar Disorder [FACE-BD]). Bipolar Disord. (2017) 19:651-60. doi: 10.1111/bdi. 12539

Conflict of Interest: The authors declare that the research was conducted in the absence of any commercial or financial relationships that could be construed as a potential conflict of interest.

Copyright (c) 2021 Etain, Olie, Courtet, Godin and Leboyer. This is an open-access article distributed under the terms of the Creative Commons Attribution License (CC $B Y)$. The use, distribution or reproduction in other forums is permitted, provided the original author(s) and the copyright owner(s) are credited and that the original publication in this journal is cited, in accordance with accepted academic practice. No use, distribution or reproduction is permitted which does not comply with these terms. 